\title{
Polyvinylpolypyrrolidoniume Tribromide as an Efficient Catalyst for the Acetylation of Alcohols and Phenols
}

\author{
Arash GHORBANI-CHOGHAMARANI", Nasrin POURBAHAR \\ Department of Chemistry, Faculty of Science, Ilam University, PO Box 69315516, Ilam, Iran
}

\begin{abstract}
An efficient and versatile procedure for the acetylation of alcohols and phenols using acetic anhydride in the presence of a catalytic amount of polyvinylpolypyrrolidoniume tribromide has been successfully developed. Primary, secondary, and tertiary alcohols, as well as a selection of the phenolic compounds, have been successfully acetylated according to this procedure, with good to high yields being achieved over short reaction times.
\end{abstract}

Key words: alcohol; phenol; polyvinylpolypyrrolidoniume tribromide; acetylation; acetic anhydride

CLC number: O643 Document code: A

Received 17 February 2012. Accepted 7 May 2012.

*Corresponding author.Tel: +98-841-2227022; Fax: +98-841-2227022; E-mail: arashghch58@yahoo.com,a.ghorbani@mail.ilam.ac.ir This work was supported by the Research Facilities of Ilam University.

English edition available online at Elsevier ScienceDirect (http://www.sciencedirect.com/science/journal/18722067).

The acetylation of alcohols and phenols is one of the most widely used transformations in organic synthesis. Organic esters represent an important family of intermediates and they are frequently employed in the synthesis of fine chemicals, perfumes, drugs, food preservatives, plasticizers, and pharmaceuticals [1-5]. Further to this, the acetylation of the hydroxyl group is often used as a protection technique in organic synthesis because of the ease of formation as well as the mild conditions required for the subsequent deprotection [6]. Acid anhydrides and acid halides are usually used as acetylating agents in the presence of an appropriate catalyst or activator [7-12].

Although many synthetic methods have been reported for the acetylation of the hydroxyl group, these approaches are invariably limited by the formation of undesired by-products, the requirement for harsh reaction conditions, low product yields, and long reaction times. With this in mind, the development of a general, mild, and novel procedure is required to prepare $O$-acetylated compounds in the presence of an appropriate catalyst.

Polymer-supported reagents have received considerable attention in recent years in the development of novel organic reaction methodologies [13-17] because of their heterogeneous nature, which enables reactions to be conducted under mild conditions and for the organic products to be isolated with relative ease from the reaction media. Furthermore, these systems show low toxicity. Taken together, the special properties associated with polymeric reagents prompted us to investigate their application in organic synthesis.

\section{Experimental}

All of the chemicals used in the current study were purchased from the Fluka, Merck, and Aldrich chemical companies. The acetylated products were characterized by comparison of their spectral (IR, ${ }^{1} \mathrm{H}$ NMR, and ${ }^{13} \mathrm{C}$ NMR) and physical data with those of the authentic samples. Polyvinylpolypyrrolidoniume tribromide was prepared according to a procedure previously reported by our group [13].

Polyvinylpolypyrrolidoniume tribromide $(0.011 \mathrm{~g})$ was added to a stirred solution of 4-iso-propylbenzyl alcohol $(0.15 \mathrm{~g}, 1 \mathrm{mmol})$ and acetic anhydride $(0.255 \mathrm{~g}, 2.5 \mathrm{mmol})$ in acetonitrile $(5 \mathrm{ml})$ and the resulting mixture was stirred at room temperature for $15 \mathrm{~min}$. Upon completion of the reaction, as determined by TLC analysis, water $(5 \mathrm{ml})$ was added to the mixture with stirring and the product mixture was extracted with $\mathrm{CH}_{2} \mathrm{Cl}_{2}(5 \mathrm{ml} \times 4)$. The combined organic extracts were dried over anhydrous $\mathrm{Na}_{2} \mathrm{SO}_{4}(1.5 \mathrm{~g})$ and concentrated to dryness by evaporated to give the desired product $(0.186 \mathrm{~g}, 97 \%$ yield $)$.

3-Fluorobenzyl acetate. ${ }^{1} \mathrm{H}$ NMR $\left(400 \mathrm{MHz}, \mathrm{CDCl}_{3}\right): \delta$ 7.40-7.46 (m, 1H), 7.14-7.21 (m, 3H), $5.10(\mathrm{~s}, 2 \mathrm{H}), 2.07$ (s, $3 \mathrm{H}) ;{ }^{13} \mathrm{C}$ NMR $\left(100.6 \mathrm{MHz}, \mathrm{CDCl}_{3}\right): \delta 170.68,162.6(\mathrm{~d}$, $\left.J_{\mathrm{C}-\mathrm{F}}=968 \mathrm{~Hz}\right), 139.6\left(\mathrm{~d}, J_{\mathrm{C}-\mathrm{F}}=32 \mathrm{~Hz}\right), 130.9\left(\mathrm{~d}, J_{\mathrm{C}-\mathrm{F}}=32\right.$ $\mathrm{Hz}), 122.5\left(\mathrm{~d}, J_{\mathrm{C}-\mathrm{F}}=12 \mathrm{~Hz}\right), 114.9-115.3(2 \mathrm{C}), 65.0,21.1$.

\section{Results and discussion}

We developed a particular interest in the application of polyvinylpolypyrrolidoniume tribromide (Scheme 1) [18], 


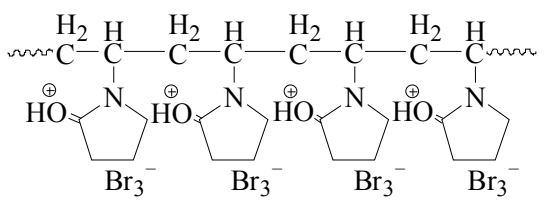

Scheme 1. Structure of polyvinylpolypyrrolidoniume tribromide.

as an efficient, green, and versatile polymeric catalyst for the protection of alcohols and phenols as the corresponding acetyl esters.

In a continuation of our ongoing efforts to develop novel applications of polymeric reagents or catalysts in organic reactions [19-24], polyvinylpolypyrrolidoniume tribromide was investigated as a green catalyst for the preparation of $O$-alkyl and aryl acetylated compounds.

Polyvinylpolypyrrolidoniume tribromide was prepared via the combination of polyvinylpolypyrrolidone with hydrobromic acid followed by the reaction of resulting salt with bromine [18].

To identify an appropriate solvent for the transformation, a screening process was conducted involving the acetylation of 2-phenylethanol in several different solvents. The results of the screening process have been summarized in Table 1 . The results in Table 1 clearly show that acetonitrile was the best solvent, in terms of reactivity, for the polyvinylpolypyrrolidoniume tribromide catalyzed acetylation reaction of 2-phenylethanol with acetic anhydride. Acetonitrile was therefore applied as the solvent for all of the subsequent
Table 1 Acetylation of 2-phenylethanol with acetic anhydride in the presence of a catalytic amount of polyvinylpolypyrrolidoniume tribromide in different solvents

\begin{tabular}{lcc} 
& \\
Solvent & Time (min) & Yield $^{\mathrm{a}}(\%)$ \\
\hline Chloroform & 300 & 81 \\
Acetonitrile & 25 & 91 \\
$n$-Hexane & 1440 & $66^{\mathrm{b}}$ \\
Dichloromethane & 270 & 92 \\
Ethyl acetate & 100 & 95 \\
Acetone & 180 & 86 \\
\hline
\end{tabular}

Reaction conditions: substrate $1 \mathrm{mmol}$, catalyst $0.011 \mathrm{~g}$, acetic anhydride $2.5 \mathrm{mmol}$.

${ }^{\mathrm{a}}$ Isolated yield.

${ }^{\mathrm{b}}$ Product purified by short-column chromatography.

acetylation reactions.

Having established the best solvent for the procedure, we proceeded to investigate the scope polyvinylpolypyrrolidoniume tribromide catalyzed acetylation reaction. Consequently, herein we disclose a novel catalytic protocol for the acetylation of primary, secondary, and tertiary alcohols, as well as a selection of phenolic compounds, using acetic anhydride and a catalytic amount of polyvinylpolypyrrolidoniume tribromide under mild and heterogeneous conditions at room temperature (Table 2).

Table 2 Acetylation of alcohols and phenols using acetic anhydride in the presence of a catalytic amount of polyvinylpolypyrrolidoniume tribromide in acetonitrile at room temperature

Entry


Table 2 (Continued)

Entry

Reaction conditions: substrate $1 \mathrm{mmol}$, catalyst $0.011 \mathrm{~g}$, acetic anhydride $2.5 \mathrm{mmol}$.

${ }^{\mathrm{a}}$ Isolated yield. ${ }^{\mathrm{b}}$ In the absence of catalyst. ${ }^{\mathrm{c}}$ No reaction. ${ }^{\mathrm{d}}$ Product purified by short column chromatography.

The acetylation of alcohols and phenols was easily achieved by the mixing $1 \mathrm{mmol}$ of the alcohol or phenol with $0.011 \mathrm{~g}$ of polyvinylpolypyrrolidoniume tribromide and $2.5 \mathrm{mmol}$ of acetic anhydride in acetonitrile, with the resulting mixture then being stirred at room temperature for the appropriate time period (Table 2). Upon completion of the reaction, the mixture was quenched by the addition of water and the pure products isolated with relative ease via the extraction of the reaction mixture with dichloromethane. It is clear from Table 2 that unhindered alcohols reacted faster than the hindered ones. To highlight the catalytic role of polyvinylpolypyrrolidoniume tribromide in the described reaction system, 2-phenylethanol was subjected to the acetylation procedure in the absence of the catalyst (Table 2, entry 11). The result clearly demonstrates the catalytic role of polyvinylpolypyrrolidoniume tribromide in the reaction of 2-phenylethanol with acetic anhydride, as the reaction in the absence of the catalyst gave none of the desired product following a $24 \mathrm{~h}$ reaction period.

A possible mechanism for this polyvinylpolypyrrolidoniume tribromide-catalyzed transformation is depicted in Scheme 2.

\section{Conclusions}

A novel polyvinylpolypyrrolidoniume tribromide catalyzed procedure for the acetylation of alcohols and phenols with acetic anhydride was successfully developed. The procedure employs a polymeric catalyst and provides a simple and effective procedure for the preparation of alkyl and aryl

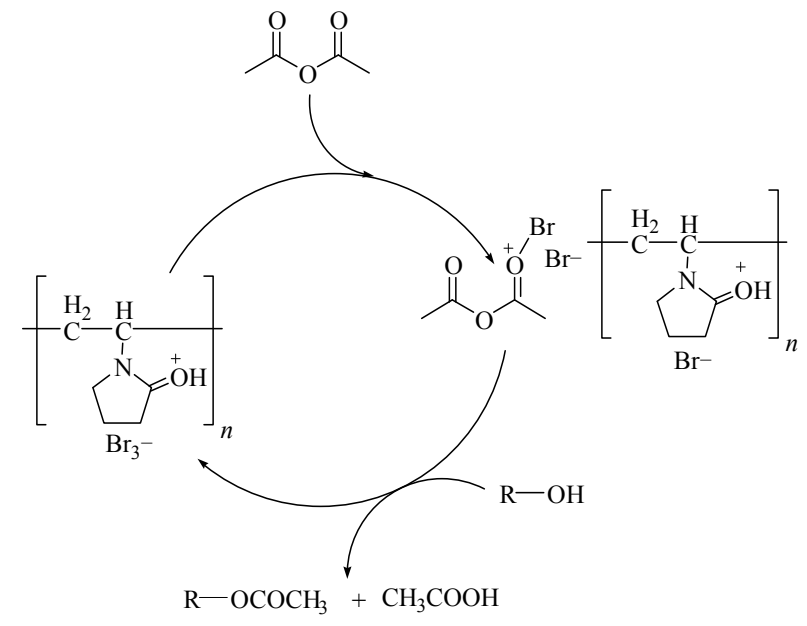

Scheme 2. Possible mechanism for acetylation of alcohols.

acetates in good to excellent yields with high purity. This procedure is characterized by heterogeneous and mild reaction conditions, non-toxic content and an easy reaction work-up, making it ideal for both laboratory and large-scale preparations.

\section{References}

1 Mrozek L, Dvorakova L, Mandelova Z, Rarova L, Rezacova A, Placek L, Opatrilova R, Dohnal J, Paleta O, Kral V, Drasar P, Jampilek J. Steroids, 2011, 76: 1082

2 Schilter B, Scholz G, Seefelder W. Eur J Lipid Sci Technol, 2011, 113: 309 
3 Nagase R, Matsumoto N, Hosomi K, Higashi T, Funakoshi S, Misaki T, Tanabe Y. Org Biomol Chem, 2007, 5: 151

4 Zoller A, Marcilla A. J Appl Polym Sci, 2011, 121: 1495

5 Verdelet T, Mercey G, Correa N, Jean L, Renard P Y. Tetrahedron, 2011, 67: 8757

6 Ghosh R, Maiti S, Chakraborty A. Tetrahedron Lett, 2005, 46: 147

7 Moghadam M, Tangestaninejad S, Mirkhani V, Mohammadpoor-Baltork I, Babaghanbari M, Zarea M, Shariati L, Taghavi S A. J Iran Chem Soc, 2009, 6: 523

8 Kim J G, Jang D O. Bull Korean Chem Soc, 2009, 30: 1435

9 Kadam S T, Lee H, Kim S S. Bull Korean Chem Soc, 2009, 30: 1071

10 Zolfigol M A, Khazaei A, Ghorbani-Choghamarani A, Rostami A, Hajjami M. Catal Commun, 2006, 7: 399

11 Rezaei-Seresht E, Mohammadi-Zonoz F, Estiri M, Tayebee R. Ind Eng Chem Res, 2011, 50: 1837

12 Shirini F, Imanzadeh G H, Mousazadeh S A R, Mohammadpoor-Baltork I, Abedin M. Chin Chem Lett, 2010, 21: 1187

13 Karimi-Zarchi M A, Mirjalili B F, Shamsi-Kahrizsangi Z, Tayefi M. J Iran Chem Soc, 2010, 7: 455

14 Ghorbani-Choghamarani A, Chenani Z, Mallakpour S. Synth Commun, 2009, 39: 4264

15 Chari M A, Syamasundar K. Catal Commun, 2005, 6: 67

16 Iranpoor N, Tamami B, Niknam K. Can J Chem, 1997, 75:
1913

17 Mirkhani V, Moghadam M, Tangestaninejad S, Hajibagheri S. J Iran Chem Soc, 2010, 7: 641

18 Ghorbani-Choghamarani A, Goudarziafshar H, Zamani P. Chin Chem Lett, 2011, 22: 1207

19 Ghorbani-Choghamarani A, Zolfigol M A, Hajjami M, Darvishi K, Gholamnia L. Collect Czech Chem Commun, 2010, 75: 607

20 Ghorbani-Choghamarani A, Azadi G. J Iran Chem Soc, 2011, 8: 1082

21 Ghorbani-Choghamarani A, Norouzi M. Bull Korean Chem Soc, 2011, 32: 1399

22 Ghorbani-Choghamarani A, Nikoorazm M, Goudarziafshar H, Abbasi M. Bull Korean Chem Soc, 2011, 32: 693

23 Ghorbani-Choghamarani A, Sardari S. J Sulfur Chem, 2011, 32: 63

24 Ghorbani-Choghamarani A, Sardari S. Chin J Catal, 2010, 31: 1347

25 Shivani, Gulhane R, Chakraborti A K. J Mol Catal A, 2007, 264: 208

26 Yadegari M, Moghadam M, Tangestaninejad S, Mirkhani V, Mohammadpoor-Baltork I. Polyhedron, 2011, 30: 2237

27 Hosseini-Sarvari M, Sharghi H. Tetrahedron, 2005, 61: 10903

28 Karimi B, Maleki J. J Org Chem, 2003, 68: 4951

29 Farhadi S, Taherimehr M. Catal Commun, 2008, 9: 703 